\title{
Bringing citizen monitoring into land management: a case study of the Bosque Ecosystem Monitoring Program
}

\section{Rowan Converse, Dan Shaw, Kim Eichhorst and May Leinhart}

\begin{abstract}
Despite the rapid expansion of citizen-based monitoring, data from these programs remain underutilized by natural resource managers, perhaps due to quality and comparability issues. We present the Bosque Ecosystem Monitoring Program as a case study of an initiative successfully meeting long-term monitoring needs of federal, state, tribal, and local natural resource managers, and informing public policy. To maximize potential for partnerships with managers, we recommend the creation of a five-year plan including scientific goals and financial solvency strategies prior to establishing a citizen science program, and offering multiple platforms for data-sharing and dialogue.
\end{abstract}

Keywords

Citizen science; Public engagement with science and technology; Science and policy-making

Citizen science programs, student-scientist partnerships, and other programs involving members of the public in scientific research have been rapidly expanding in number and gaining broader scientific credibility [Dickinson et al., 2012]. Such programs can represent an opportunity for increased public outreach and expanded geographic and temporal range of monitoring, at a lower cost in terms of data points gathered per dollar [Dickinson, Zuckerberg and Bonter, 2010; Gardiner et al., 2012]. Although these attributes would seem to make citizen-collected datasets imminently useful for governmental natural resource managers who have seen budgets for environmental monitoring decline over the past twenty years [Gray and Shimshack, 2011], it appears that there have been few published confirmations of the use of citizen-collected data by natural resource managers to inform public policy [Conrad and Daoust, 2008; Conrad and Hilchey, 2011]. Conrad and Hilchey [2011], in a review of citizen environmental monitoring programs worldwide, identified the lack of case studies on this issue as a key gap in the literature of citizen science.

While there are a number of factors speculated to be impacting the incorporation of citizen science data into governmental databases, concerns about the quality of data collected by nonspecialists may be one of the most salient. Indeed, several evaluations of volunteer-collected data in the literature have shown that data collected by nonspecialists tend to be somewhat less accurate than data collected by professional scientists [e.g. Brandon et al., 2003; Delaney et al., 2008; Engel and 
Voshell, 2002]. However, volunteer-collected data worldwide have been shown to be sufficiently comparable to data collected by professionals for the purpose of statistical analysis, particularly if citizen science groups work with professionals in designing appropriate protocols [Engel and Voshell, 2002; Danielsen et al., 2014]. Problems with inconsistent protocols, lack of comparability with established governmental monitoring methods, and data quality standards for court admissibility may also limit the use of volunteer-collected data by natural resource managers [Conrad and Daoust, 2008; Penrose and Call, 1995]. The perception of informality on the part of some citizen science programs may also detract from their credibility; in a survey regarding the goals of citizen science practitioners, Dickinson and Bonney [2012] observed a tradeoff favoring education and outreach rather than production of scientific research.

Despite these obstacles, the need for high-quality, long-term environmental datasets is inescapable [Lovett et al., 2007]; equally or more so the need for a scientifically literate public [Bestelmeyer et al., 2015]. We believe that these two needs can be met in a cost-effective manner through the establishment of citizen science programs. We can demonstrate that the difficulties in establishing data-sharing partnerships with natural resource managers are surmountable and that a local program can deliver timely, relevant data to managers while providing valuable educational experiences in science to a largely underserved population. We present the Bosque Ecosystem Monitoring Program (BEMP) as a case study.

\section{Case study}

BEMP is a nonprofit partnership between the University of New Mexico (UNM) and the independent Bosque School in Albuquerque, New Mexico, and since 1998 has been the official schoolyard outreach of the Sevilleta Long-Term Ecological Research site. The mission of BEMP is "science, education, and stewardship of the Rio Grande and its watershed through long-term, hands-on student research of ecosystem response and function to inform policy" [BEMP, 2015]. Since 1997, BEMP has involved kindergarten through twelfth grade (primary and secondary school) students, especially ages ten to eighteen, in collecting ecological data at thirty permanent research sites in the riparian forest adjacent to the Rio Grande, locally known as the bosque (Spanish for "forest") (Figure 1).

These school groups, supervised by BEMP staff and university interns, collect depth to shallow groundwater, leaf litter fall, and precipitation data on a monthly basis, as well as surface-active arthropod data three times per year (Figure 2). These variables were chosen for long-term monitoring based upon research by Ellis, Crawford, and Molles into the dynamics of the bosque ecosystem [1996]. Groundwater is a primary driver of vegetation dynamics in the bosque, leaf litter can serve as a proxy measure for net primary production (as well as provide some insight into native vs exotic species dynamics), and certain arthropod assemblages are strongly associated with different ecological conditions in the bosque, and thus can provide insight into the impacts of different land management strategies. The equipment used to monitor these processes is inexpensive and widely available: for example, pitfall traps for arthropods consist of two plastic cups dug into the ground and covered with a $4 \times 4$ in (approximately $10 \times 10 \mathrm{~cm}$ ) board. Further detail on BEMP's monitoring methods can be found at its website. ${ }^{1}$

\footnotetext{
${ }^{1}$ http:/ / bemp.org/research-guides-protocols/.
} 


\section{SBEMP \\ Our Sites}

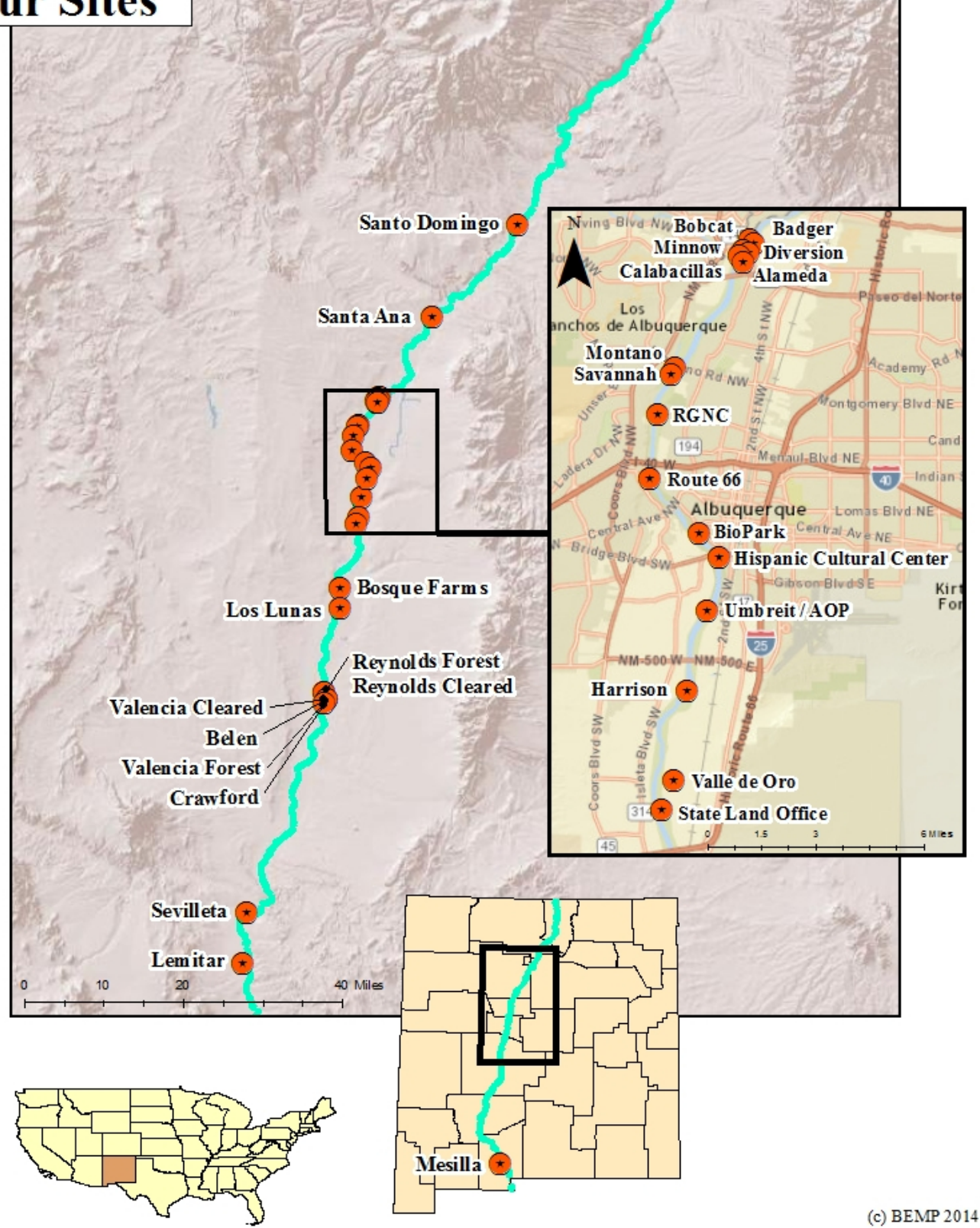

Figure 1. Overview of BEMP's 30 permanent monitoring sites in the Middle Rio Grande Valley in New Mexico, spanning roughly 300 miles (about $480 \mathrm{~km}$ ) of the Rio Grande from Ohkay Owingeh Pueblo to Mesilla Valley Bosque State Park in Las Cruces. Sixteen of BEMP's sites are located in Albuquerque, the most populous city in New Mexico.

Each BEMP site has a long-term "site representative", generally a teacher, who oversees monthly data collection along with BEMP staff. Thus, the same class of children monitors the same site over the course of an academic year to provide a chance for deeper engagement with and understanding of the bosque ecosystem. While field protocols for monthly monitoring are the same regardless of academic level, BEMP works with teachers to tailor accompanying locally-focused 


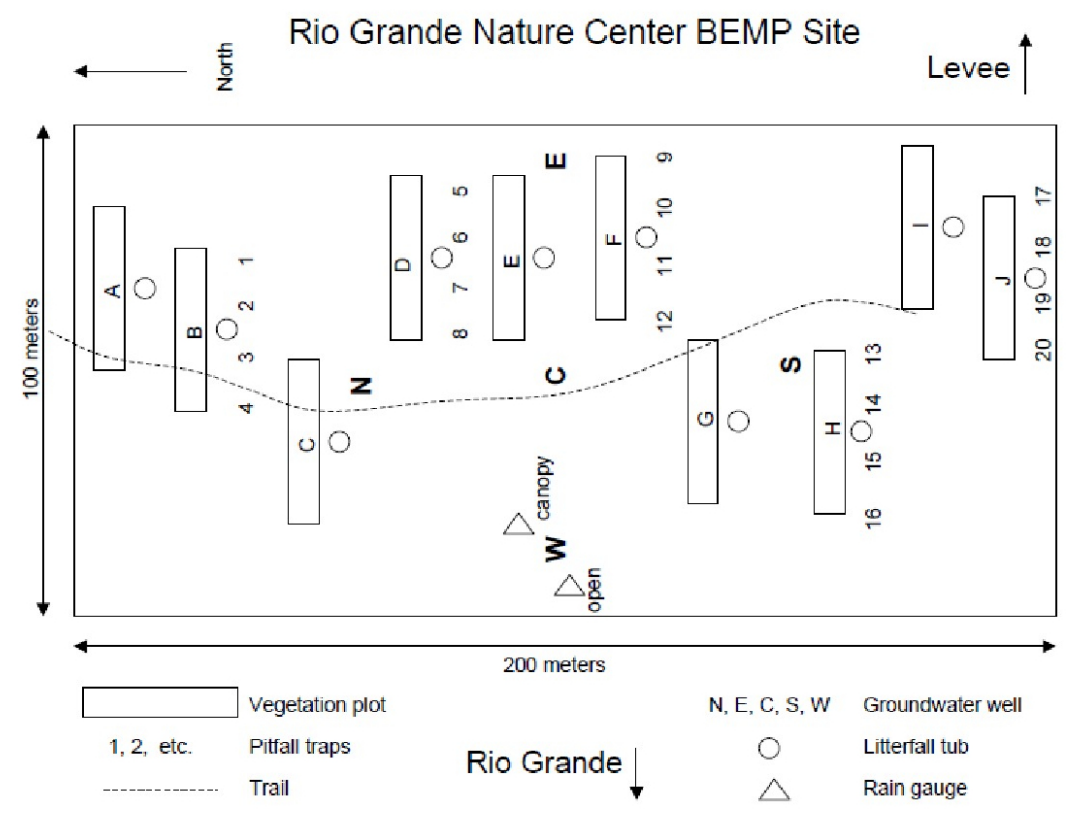

Figure 2. Each of BEMP's thirty research sites shares a common setup: an array of five shallow groundwater wells surveyed for height and elevation, ten randomly-placed leaf litterfall bins to survey the ten most common canopy and understory species, ten vegetation transects inventoried annually by professional botanists, two precipitation gauges (one in the open and one under the canopy), and twenty pitfall traps for surface-active arthropods. All sites are located adjacent to the Rio Grande.

environmental education lessons to the needs of each class, which can be quite diverse: the needs of a high school class at an urban, environmentally-focused school will be different from those of a middle school class of Native American students at a tribal school, for example. BEMP's lesson plans are crafted to meet state and national standards for educational reform to ease their incorporation into classrooms. This education and outreach helps to meet a pressing need for science education in New Mexico; in certain primary schools, BEMP's environmental education is the only science education offering. BEMP reaches over 10,000 students, teachers, and other members of the public with its environmental education and outreach, about a quarter of whom are involved in monthly data collection.

BEMP staff and other professionals also collect several "extra" datasets outside of regular monthly monitoring, funding permitting, on a seasonal or annual basis. Examples of "extra" monitoring include vegetation inventory and percent cover, groundwater chemistry, river and ditch water quality, and fuel load and woody debris analysis.

BEMP data are actively utilized by a variety of local, state, federal, and tribal land management agencies to inform policy affecting the bosque. Two thirds of BEMP sites were installed at the request of governmental land managers in order to monitor the long-term impacts of riparian restoration projects. We will describe BEMP's history of establishment and methods of engagement with natural resource managers, and provide an overview of local policy informed by BEMP data and research. Five of BEMP's natural resource management partners were interviewed in order to evaluate the impact of BEMP data on decision-making regarding the bosque. 
Over the course of its eighteen-year history, BEMP has cultivated data-delivery partnerships with a variety of governmental land management agencies operating in the Middle Rio Grande Valley. About fifteen of these partnerships are ongoing; however, some are no longer active. For the purpose of this study, we interviewed representatives from five agencies with active partnerships. The five interview subjects were the United States Army Corps of Engineers (COE), the Interstate Stream Commission (ISC), the New Mexico State Land Office (SLO), the Middle Rio Grande Conservancy District (MRGCD), and the City of Albuquerque Open Space Division (CABQ). The selected agencies represent different levels of governmental management with which BEMP partners: federal (COE), state (ISC, SLO), and local (county/district: MRGCD; city: CABQ). Some of these agencies represent long-standing partnerships representing a significant portion of BEMP's funding (COE, MRGCD, CABQ); others represent relatively new partnerships still in development (SLO).

Interviews were conducted with representatives of the five agencies in a free-response style over the phone or, in one case, over e-mail due to time constraints. Each interview subject was asked the following questions:

- Which BEMP datasets does your agency actively utilize? What kinds of projects are they used to inform?

- Can you identify any changes to your agency's bosque-related practices or policy informed, in part or in whole, by BEMP data?

- What method or methods do you use to access BEMP data: BEMP's website, technical reports, annual data users' meeting/Fall Field Tour/other events? Which of these is the most useful?

- How did your agency become interested in utilizing BEMP data?

- Are there any obstacles you can identify, either past or current, to using BEMP data to inform your agency's work?

A summary of key ideas synthesized from these interviews is incorporated into the following case study.

Establishment and forming partnerships
In 1992, an interagency team of federal and university biologists was tasked with providing an overview of the state of knowledge about the bosque in central New Mexico, and forming recommendations for management to encourage "biological quality" and "ecosystem integrity" of that system [Crawford et al., 1993]. In the report produced, the Bosque Biological Management Plan, one of the team's central recommendations was the establishment of a centralized, long-term ecological monitoring program whose data would be accessible to all land managers in the Middle Rio Grande Valley [Crawford et al., 1993].

Graduate research by a student of the primary author of the Bosque Biological Management Plan provided evidence that middle school age students could reliably collect ecological monitoring data in the bosque [Stuever, 1997]. Further, the researchers of the Plan had noted a need for public education about "the 
Bosque and its dynamics to help motivate activities to protect the Bosque and balance its uses" [Crawford et al., 1993]. Thus, biologists at UNM and educators at the Bosque School, an independent school focused on arts and environmental education, partnered to create the organization that eventually became BEMP. The team drew from the structure of both national programs like Project WILD [Western Regional Environmental Education Council, 1992], and local programs like New Mexico Watershed Watch. Project WILD is an environmental education program whose major innovation was linking professional wildlife biologists and classroom teachers to develop curricula that were both ecologically accurate and classroom-suitable; New Mexico Watershed Watch involves high school students in the state in monitoring water quality in their local streams and rivers. Following those models, BEMP biologists and educators worked together to craft protocols that would be scientifically rigorous and comparable with those used by governmental agencies, as well as developmentally appropriate and consistently replicable for use by students of a variety of ages: all protocols were field-tested with multiple groups of students prior to incorporation in the program. The educators further worked to craft lesson plans about the bosque ecosystem that would complement and build upon the data collection excursions, drawing both from national curricula such as Project WILD, Project Learning Tree [Comnes et al., 1993], and Project WET [Higgins, Kesselheim and Robinson, 1995], as well as locally-focused curricula like the Bosque Education Guide [Stuever et al., 1995].

BEMP was established with funding from a National Science Foundation informal education grant, beginning with four sites in 1997 [Valett and Campana, 1996]. Early on, a BEMP intern class was created at the University of New Mexico to, among other goals, deploy senior-level undergraduate and graduate students in serving in a data quality control role with kindergarten through twelfth grade BEMP students.

While the program was initially funded by education grants, within five years the primary funding source transitioned to data delivery contracts with natural resource managers. Some of these partnerships were formed almost immediately: several agencies involved in the creation of the Bosque Biological Management Plan were interested in BEMP data very early in the program's establishment. Other agencies became interested after learning of BEMP by issuing permits for BEMP activities carried out on land under their jurisdiction, as stated by two managers in interviews [Schmader, 2015; Najmi, 2015]. BEMP staff made extensive efforts to contact governmental agencies and inquire about their data needs. This occasionally led to contracts for BEMP to collect ecological datasets outside of BEMP's regular monthly monitoring. The "extra" monitoring datasets were critical to sustaining the program by securing additional funding and paving the way for long-term partnerships. However, from year to year BEMP sometimes lacked the resources to consistently collect all of the additional datasets at all sites of interest, perhaps constraining the overall usefulness of these "extra" datasets within the scope of BEMP's vision of providing long-term, rather than snapshot, datasets. Finally, as BEMP became a more established program, some agencies took interest in BEMP due to its long-standing reputation; as one manager put it in an interview, the opportunity to contribute to a broad-based body of research is, "not something you get very often" [Najmi, 2015]. 
Data quality control
Demonstrable and consistent data quality control is a necessity for working with governmental land management agencies, which often must adhere to strict standards for court admissibility for any data used in the decision-making process. BEMP's method of ensuring data quality is extensive supervision and vetting of all data by trained staff members at every stage of collection, processing, and analysis.

In the field, school groups are supervised by at least one BEMP staff member or experienced site representative, and typically one or two university interns. Supervising staff members typically hold at least a completed bachelor's degree in biology or a related field, and have at least six months' experience in collecting monthly monitoring data. Supervising site representatives are generally long-term participants in the program, with at least 2-3 years of experience.

All BEMP data are processed at the University of New Mexico, and must be verified by BEMP's data manager prior to incorporation in BEMP's official database. Outliers are flagged and the data manager consults outside evidence, such as field notes taken by staff or other verified data, to resolve the issue. Notes are included in the data documentation to explain the rejection or acceptance of questionable data.

Physical samples requiring identification as part of processing, such as leaf litter fall or surface-active arthropods, are processed under the supervision of BEMP staff, either at a laboratory on the UNM campus by university interns, or in the classrooms of secondary school students involved in monthly monitoring. When a higher level of identification expertise is required, such as for some surface-active arthropod samples, staff members with the appropriate knowledge and skillset conduct the processing.

Datasets requested by agencies requiring more complex field methods or even stricter data quality controls, such as water quality monitoring, are collected by BEMP staff with the help of university interns, with the exception of vegetation inventory monitoring, which is contracted to professional botanists annually due to the highly specialized skill set required. Even these outside professionals sometimes utilize graduate, undergraduate, and even high school BEMP interns as field assistants.

The obvious drawback to this framework of data quality control is the large amount of staff time required. However, we have observed a payoff in the quality of data received under extensive supervision. This data quality subsequently encourages use by land managers, and therefore increases their investment in the program.

Another major drawback is the limited opportunity for students to be involved beyond the data collection phase. BEMP is currently working to expand opportunities for student research by hiring a full-time staff member to mentor secondary school students interested in pursuing research opportunities and to craft new protocols to broaden access to research opportunities for underserved students. 
Maintaining partnerships
BEMP and public policy
BEMP offers four main platforms to engage data users and encourage accessibility: reports published through UNM Biology, presentations to specific agencies, a website, and hosted events.

Print reports with summary and analysis of BEMP's monthly monitoring and "extra" datasets are released through UNM Biology on an annual basis or at other intervals of interest (5-year, 10-year, etc). Three of five managers stated that the reports were their primary method of access to BEMP data, though one noted difficulty with combing through large datasets as she searched for data of interest. Two other managers further stated that they preferred to receive data directly from BEMP's data manager so as only to receive data from particular sites of interest.

All of BEMP's data are non-proprietary and available to the public online. Both data and reports are accessible through the website. While only one manager stated that the website was her primary access point to BEMP data, three other managers stated that they also have used the website for access to BEMP data at some point, one saying that it provided an easy, at-a-glance overview of the kind of data available. Inquiries through the website by managers as well as members of the public have led to requests for additional data, and occasionally further funding, to provide more comprehensive datasets.

BEMP has observed that creatively structured events provide a platform to discuss community data needs, provide funding opportunities, and allow for comparison of datasets collected by various agencies. BEMP hosts three events throughout the year for this purpose, some targeted particularly at the needs of data users in order to provide BEMP an opportunity for improvement, and others bringing together data users, community groups, and school-age volunteers to present research and restoration projects related to the bosque. While BEMP-hosted events were the least-used method of data access by natural resource managers, with three managers explicitly stating that the meetings were their least-preferred method of data access or that they had not attended them, comments by managers on these events included that they were useful for networking and getting more information about other agencies' bosque-related projects. Three of five managers expressed interest in attending or continuing to attend these events in the future.

Impacts

BEMP has had concrete impacts on bosque management in the Middle Rio Grande Valley. The following is not intended to be a comprehensive summary, as not all of BEMP's data-using partners were interviewed for this paper.

The most common use of BEMP data cited by agencies was the evaluation of outcomes of restoration projects: all managers interviewed indicated that this was their primary interest in BEMP data. BEMP data have sometimes led to changes in restoration practices: for example, the MRGCD adopted new guidelines for woodchip depth at sites where invasive woody species are cleared and mulched after it was observed that sites with higher mulch depth had lower native species recovery [Najmi, 2015].

Two of five natural resource managers indicated use of BEMP data prior to the commencement of restoration work. The US Army Corps of Engineers, one of 
BEMP's main funders, utilizes datasets from or near restoration project areas in the design phase of restoration work [Hummel, 2015]. The Interstate Stream Commission reported using BEMP data as baseline data to fulfill compliancy requirements prior to the commencement of new restoration projects [Lundahl, 2015]. Additionally, though not interviewed for this paper, the US Fish and Wildlife Service installed a BEMP site upon the establishment of the Valle de Oro National Wildlife Refuge in order to obtain two years of baseline ecological data prior to the commencement of a large-scale ecological recovery program.

Uses of specific datasets were variable among agencies. While depth to shallow groundwater is the most frequently requested BEMP dataset, and was the individual dataset noted most frequently (by four of five managers) as an actively used dataset, a variety of uses of various datasets were cited by managers. For example, the City of Albuquerque utilizes BEMP's groundwater data to inform revegetation strategies during restoration projects [Schmader, 2015]. Precipitation data were used to help inform forest closures during summer drought years [Najmi, 2015]. The US Army Corps of Engineers targeted certain areas for invasive species clearing and native species restoration based on BEMP vegetation transects and leaf litterfall data [Hummel, 2015].

BEMP may also have some influences that are more difficult to quantify: one manager stated that partnering with BEMP was a small step in a broader cultural shift at that agency toward long-term planning in environmental monitoring, rather than directing more resources into short-term projects with higher levels of detail.

\section{Challenges to incorporating BEMP data into policy}

Contrary to the concern that quality limits the use of data collected by non-specialists to inform policy [Conrad and Daoust, 2008], none of BEMP's data-using partners noted this as an obstacle, when asked to identify any perceived obstacles to using BEMP's data to inform policy. The main issues cited by managers were: other political issues impacting management decisions (two managers), not understanding how certain variables related to each other or the significance of certain findings (stated by two managers who were not trained as biologists or ecologists), issues with timely data delivery (two managers), difficulty in sorting through a large database (one manager), gaps in data collection (one manager), and perceived problems of statistical explanatory power in the essential design of the program (one manager, stated with the caveat that this was a problem he felt applied to much ecological research). One manager did not note any perceived obstacles to incorporating BEMP data into policy.

Recommendations and lessons learned
For citizen science programs in the early phases of establishment, we recommend drafting a five-year plan with particular attention to scientific goals and financial solvency strategies. We suggest referencing Whitelaw and colleagues' [2003] recommendations for establishing community-based monitoring programs, as well as Conrad and Daoust's [2008] follow-up to Whitelaw and colleagues' framework, to support the creation of such a plan. We wish to emphasize length of the plan: a five-year window is a rough estimate of the time required to amass a dataset of sufficient size and longevity to 1 ) enable the observation of ecological trends, 
2) allow for data comparisons with agencies who may only collect certain environmental monitoring datasets every few years, and 3) build familiarity and credibility within the community. This last point is critical: two of the managers we spoke with indicated that they were familiar with BEMP's reputation prior to establishing a data-delivery partnership.

BEMP has found that engaging as broad an array of managers as possible provides greater financial stability. The development of a diverse funding stream may be a more sustainable long-term strategy than dependence on a few larger grants. However, data-delivery contracts often only extend for 1-2 years, which can make long-term planning and expansion difficult.

Careful attention must be paid to the selection of both methodology and ecological processes to monitor in order to balance feasibility and ecological relevance.

BEMP's selection of ecological variables for monthly monitoring was informed by prior research on the ecological dynamics of the bosque [Ellis, Molles and Crawford, 1996], and further narrowed by the process of developing field protocols suitable for use with students. All of BEMP's monthly monitoring methods were vetted with multiple sample groups of primary and secondary-age students to ensure consistency across multiple site visits, as well as educational value, prior to formal adoption in the program. Consistency in data protocols and collection is critical to maintain credibility and comparability of long-term data. Where possible, we suggest utilizing the same or comparable methods as the land managers of interest in order to streamline adoption of data. Many governmental agencies will require demonstrable data quality control processes that meet stringent standards for court admissibility in order to incorporate data into decision-making processes. Finally, variables for monitoring should be chosen to maximize statistical explanatory power over the long term [Legg and Nagy, 2006].

Offering multiple platforms for engagement with natural resource managers is important to maintaining partnerships, as different agencies will necessarily have different interests and levels of engagement, particularly with projects covering large geographic areas under multiple jurisdictions. Having data publicly accessible in an online, centralized database is probably the simplest method for meeting a broad spectrum of data-use needs. A future direction for BEMP may be to make its online database more flexible and searchable in order to meet the needs of managers who noted difficulties with sorting through a multivariate, eighteen-year database spanning thirty research sites.

Finally, we wish to make at least a brief note of the impacts of participation on students involved with BEMP. Natural resource managers are not the only beneficiaries of data collected by students involved with BEMP — the students themselves derive benefit from classroom use of data by learning data analysis and ecology, for example. BEMP has measured educational outcomes via teacher surveys since 2001. Surveys are multiple choice in format, questions varying slightly from year to year, with a free response section for additional comments. They are administered in paper format or through an online survey platform. Participation is encouraged via in-person and e-mail follow-up but otherwise no incentive is given. The number of teachers surveyed has been variable depending on the number involved in the program from year to year, and response rate has been similarly variable, from $37.5 \%$ to $100 \%$. When asked about the goals of their 
participation in BEMP, teachers have cited similar reasons over time: to give students the opportunity to learn about their local environment, to engage them in hands-on, service-oriented learning, and to have the opportunity to involve them in "real science" with applications beyond the classroom [Shaw, Gebauer and Eichhorst, 2005; BEMP, 2013]. For the most recent year of available data (2012-2013), by teachers' own accounting, the program serves these goals well. On questions relating to perceptions of students' understanding of the science of the program and its broader implications, as well as engagement and interest in the bosque environment, the vast majority (between $88-100 \%$ on all six questions) agreed strongly or somewhat that their students had gained proficiency or improvement in these areas due to their participation in BEMP [BEMP, 2013]. Diverse anecdotal reports underscore the deep personal impacts BEMP has on its participants. In open-ended commentary on the aforementioned teacher assessment surveys, some teachers cited cultural opportunities for Native American students as a major reason for participation in the program, while others noted benefits for at-risk students in their classrooms [Shaw, Gebauer and Eichhorst, 2005]. Several middle and high school students have had success in local and regional science fairs with research based on and incorporating BEMP data, while others have used their experiences with BEMP as the inspiration for award-winning community service projects [Eichhorst et al., 2012]. High school and university interns have experienced positive impacts on their later careers. Former interns $(n=66)$ were offered a multiple-choice online survey, open for one month, in 2014. Three reminder emails were sent to encourage participation, but otherwise no incentive was given to respond to the survey. Of the respondents $(n=30), 60 \%$ indicated that they had developed skills with BEMP that were useful in their later careers (with 6\% disagreeing, 7\% neutral, and 27\% not applicable), and $70 \%$ of those who had completed their schooling were currently employed in natural resource conservation, research, or management positions [Converse and Shaw, 2015].

BEMP may provide a model for some citizen science programs to raise the profile of their data to inform public policy. We hope that other citizen science programs and citizen-based monitoring groups will publish further case studies in order to explore possible alternative models for partnerships with natural resource managers, as well as to determine the real extent of the use of data collected by non-professionals in environmental decision-making. In a time of increasingly dire environmental challenges in the form of global climate change, resource limitations, and widespread ecological degradation and fragmentation, citizen science is a powerful tool for meeting the needs of multiple segments of the community and influencing positive behavioral and societal change.

References

Bestelmeyer, S. V., Elser, M. M., Spellman, K. V., Sparrow, E. B., Haan-Amato, S. S. and Keener, A. (2015). 'Collaboration, interdisciplinary thinking, and communication: new approaches to K-12 ecology education'. Frontiers in Ecology and the Environment 13 (1), pp. 37-43. DOI: 10.1890/140130.

Bosque Ecosystem Monitoring Program (2013). The Albert J. and Mary Jane Black Institute for Environmental Studies 2012-2013 year in review. Albuquerque, NM, U.S.A.: Albert J. and Mary Jane Black Institute for Environmental Studies at Bosque School. URL: http://www . bosqueschool .org/uploads/files/BEMP\%20Y ear $\% 20$ in $\% 20$ Review $\% 2012-13 \% 20$ v_2.pdf. 
Bosque Ecosystem Monitoring Program (August 2015). BEMP Overview. URL: http://www . bosqueschool .org/BEMP. aspx.

Brandon, A., Spyreas, G., Molano-Flores, B., Carroll, C. and Ellis, J. (2003). 'Can Volunteers Provide Reliable Data for Forest Vegetation Surveys?' Natural Areas Journal 23 (3), pp. 254-262. URL: http://www.discoverlife.org/pa/or/polist es/pr/2010nsf_macro/references/Brandon_et_al2003.pdf.

Comnes, L., Marshall, J., Myers, R., Moore, J., Pasternak, A. and Woelflein, L. (1993). Project Learning Tree Environmental Education Activity Guide: Pre K-8. Washington, DC, U.S.A.: American Forest Foundation.

Conrad, C. T. and Daoust, T. (2008). 'Community-Based Monitoring Frameworks: Increasing the Effectiveness of Environmental Stewardship'. Environmental Management 41 (3), pp. 358-366. DOI: 10.1007/s00267-007-9042-x.

Conrad, C. C. and Hilchey, K. G. (2011). 'A review of citizen science and community-based environmental monitoring: issues and opportunities'. Environmental Monitoring and Assessment 176 (1), pp. 273-291. DOI: $10.1007 / \mathrm{s} 10661-010-1582-5$.

Converse, R. C. and Shaw, D. (2015). 'Developing natural resource career pathways through citizen science'. Oral presentation. In: Joint Annual Meeting of the Arizona and New Mexico Chapters of the American Fisheries Society and the Wildlife Society. (Las Cruces, NM, U.S.A. February 2015).

Crawford, C. C., Culley, A. C., Leutheuser, R., Sifuentes, M. S., White, L. H. and Wilber, J. P. (1993). Middle Rio Grande Ecosystem: Bosque Biological Management Plan. Albuquerque, NM, U.S.A.: US Fish and Wildlife Service, District 2.

Danielsen, F., Jensen, P. M., Burgess, N. D., Altamirano, R., Alviola, P. A., Andrianandrasana, H., Brashares, J. S., Burton, A. C., Coronado, I., Corpuz, N., Enghoff, M., Fjeldsa, J., Funder, M., Holt, S., Hubertz, H., Jensen, A. E., Lewis, R., Massao, J., Mendoza, M. M., Ngaga, Y., Pipper, C. B., Poulsen, M. K., Rueda, R. M., Sam, M. K., Skielboe, T., Sorensen, M. and Young, R. (2014). 'A Multicountry Assessment of Tropical Resource Monitoring by Local Communities'. BioScience 64 (3), pp. 236-251. DOI: 10.1093/biosci/biu001.

Delaney, D. G., Sperling, C. D., Adams, C. S. and Leung, B. (2008). 'Marine invasive species: validation of citizen science and implications for national monitoring networks'. Biological Invasions 10 (1), pp. 117-128. DOI: 10.1007/s10530-007-9114-0.

Dickinson, J. L. and Bonney, R. (2012). 'Why Citizen Science?' In: Citizen Science: Public Participation in Environmental Research. Ed. by J. L. Dickinson and R. Bonney. Ithaca, NY, U.S.A.: Cornell University Press.

Dickinson, J. L., Zuckerberg, B. and Bonter, D. N. (2010). 'Citizen Science as an Ecological Research Tool: Challenges and Benefits'. Annual Review of Ecology, Evolution, and Systematics 41 (1), pp. 149-172. DOI: 10.1146/annurev-ecolsys-102209-144636.

Dickinson, J. L., Shirk, J., Bonter, D., Bonney, R., Crain, R. L., Martin, J., Phillips, T. and Purcell, K. (2012). 'The current state of citizen science as a tool for ecological research and public engagement'. Frontiers in Ecology and the Environment 10 (6), pp. 291-297. DOI: $10.1890 / 110236$. 
Eichhorst, K. D., Shaw, D. C., Schuetz, J. F., Scheerer, K. A., Keithley, M. and Crawford, C. S. (2012). Bosque Ecosystem Monitoring Program (BEMP) Comprehensive Report: 1997-2009. Open File Report 12-5. Albuquerque, NM, U.S.A.: University of New Mexico. URL:

http://www . bosqueschool .org/uploads/FileLinks/4647afda67484412b45f4c 35df0ca689/BEMP_comprehensive_report_FINAL_6.29.12.pdf.

Ellis, L. M., Molles, M. C. and Crawford, C. S. (1996). Seasonal Flooding and Riparian Restoration in the Middle Rio Grande Valley. Final report: Cooperative Agreement 14-16-0002-91-228. Albuquerque, NM, U.S.A.: US Fish and Wildlife Service, District 2.

Engel, S. R. and Voshell, J. R. (2002). 'Volunteer biological monitoring: can it accurately assess the ecological condition of streams?' American Entomologist 48 (3), pp. 164-177. DOI: 10.1093/ae/48.3.164.

Gardiner, M. M., Allee, L. L., Brown, P. M. J., Losey, J. E., Roy, H. E. and Smyth, R. R. (2012). 'Lessons from lady beetles: accuracy of monitoring data from U.S. and U.K. citizen-science programs'. Frontiers in Ecology and the Environment 10 (9), pp. 471-476. DOI: $10.1890 / 110185$.

Gray, W. B. and Shimshack, J. P. (2011). 'The Effectiveness of Environmental Monitoring and Enforcement: A Review of the Empirical Evidence'. Review of Environmental Economics and Policy 5 (1), pp. 3-24. DOI: 10.1093/reep/req017.

Higgins, S., Kesselheim, A. S. and Robinson, G. (1995). Project WET Curriculum and Education Activity Guide: K-12. Houston, TX, U.S.A.: Western Regional Environmental Education Council.

Hummel, O. (2015). Personal communication. United States Army Corps of Engineers (COE).

Legg, C. J. and Nagy, L. (2006). 'Why most conservation monitoring is, but need not be, a waste of time'. Journal of Environmental Management 78 (2), pp. 194-199. DOI: $10.1016 / j \cdot j$ envman.2005.04.016.

Lovett, G. M., Burns, D. A., Driscoll, C. T., Jenkins, J. C., Mitchell, M. J., Rustad, L., Shanley, J. B., Likens, G. E. and Haeuber, R. (2007). 'Who needs environmental monitoring?' Frontiers in Ecology and the Environment 5 (5), pp. 253-260. DOI: 10.1890/1540-9295 (2007) 5[253:WNEM] 2.0.CO; 2.

Lundahl, A. (2015). Personal communication. Interstate Stream Commission (ISC).

Najmi, Y. (2015). Personal communication. Middle Rio Grande Conservancy District (MRGCD).

Penrose, D. and Call, S. M. (1995). 'Volunteer Monitoring of Benthic Macroinvertebrates: Regulatory Biologists' Perspectives'. Journal of the North American Benthological Society 14 (1), pp. 203-209. DOI: 10.2307/1467735.

Schmader, M. (2015). Personal communication. City of Albuquerque Open Space Division (CABQ).

Shaw, D., Gebauer, A. and Eichhorst, K. D. (2005). Participating Teachers' Perceptions and Use of the New Mexico Watershed Watch and Bosque Ecosystem Monitoring Program. Albuquerque, NM, U.S.A.: Albert J. and Mary Jane Black Institute for Environmental Studies at Bosque School.

Stuever, M., Morris, L., Tydings, R. and Ellis, L. (1995). The Bosque Education Guide. Albuquerque, NM, U.S.A.: Friends of the Rio Grande Nature Center.

Stuever, M. C. (1997). 'Fire induced mortality in Rio Grande cottonwood'. Master's thesis. Albuquerque, NM, U.S.A.: University of New Mexico.

Valett, H. M. and Campana, M. E. (1996). Stream/Groundwater Ecotones: Hydrology, Biogeochemistry and Ecology. Grant Proposal. National Science Foundation: Division of Environmental Biology, Informal Science Education Initiative. 
Western Regional Environmental Education Council (1992). Project WILD. Bethesda, MD, U.S.A.: Project WILD.

Whitelaw, G., Vaughan, H., Craig, B. and Atkinson, D. (2003). 'Establishing the Canadian Community Monitoring Network'. Environmental Monitoring and Assessment 88 (1), pp. 409-418. DOI: 10.1023/A:1025545813057.

Authors

How to cite
Rowan Converse is a biologist with the Bosque Ecosystem Monitoring Program. She has worked in management and monitoring of a variety of wildlife species in New Mexico, including Mexican grey wolf, tamarisk leaf beetle, Mexican spotted owl, and North American river otter. E-mail: rowan.converse@bosqueschool.org.

Daniel Shaw and his Bosque School (New Mexico) students' research includes habitat and wildlife issues in urban landscapes, porcupine and other small and mid-size mammal natural history, and threats to amphibian survival. He co-directs the citizen science Bosque Ecosystem Monitoring Program (www.bemp.org). His publications include the UNM Press Southwest Aquatic Habitats: On the Trail of Fish in a Desert and Eco-tracking: On the Trail of Habitat Change.

E-mail: dan.shaw@bosqueschool.org.

Dr. Kim Eichhorst, Ph.D. is the Co-Director of the Bosque Ecosystem Monitoring Program and serves as a Research Associate Professor at the University of New Mexico. She began conducting research in the bosque in 1995, working with BEMP's cofounder Dr. Cliff Crawford, on the interaction between herbivores, cottonwoods, and pollution in urban and rural areas. E-mail: kimde@unm.edu.

May Leinhart began working as BEMP's Stewardship Coordinator in 2014, after amassing nearly a decade of conservation and non-profit experience in the southeastern United States. She graduated from the University of the South at Sewanee with a degree in English and environmental studies. May also completed a master's degree in Geography at Appalachian State University, where she researched the spatial evolution of political flood plain management systems along the Mississippi. E-mail: may.leinhart@bosqueschool.org.

Converse, R., Shaw, D., Eichhorst, K. and Leinhart, M. (2016). ‘Bringing citizen monitoring into land management: a case study of the Bosque Ecosystem Monitoring Program'. JCOM 15 (03), A02. 